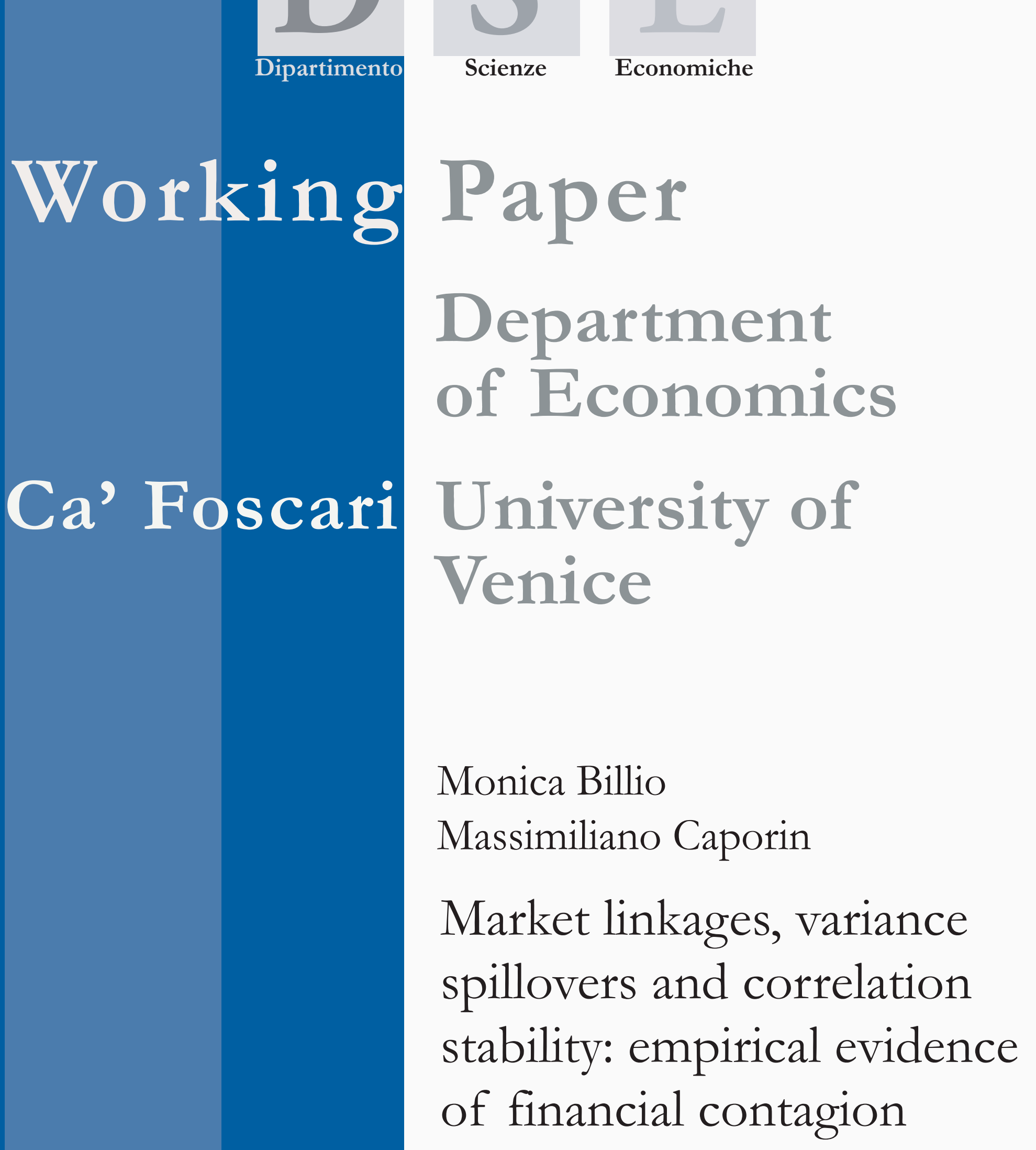




\title{
Market linkages, variance spillovers and correlation stability: empirical evidences of financial contagion ${ }^{1}$
}

\author{
Monica Billio \\ University of Venice and SSAV, Scuola Studi Avanzati in Venezia
}

\section{Massimiliano Caporin}

University of Padova

\begin{abstract}
We propose a simultaneous equation system with GARCH errors to model the contemporaneous relations among Asian and American stock markets. On the estimated residuals, we evaluate the correlation matrix over rolling windows and introduce a correlation matrix distance, which allows both a graphical analysis and the development of a statistical test of correlation movements. Furthermore, we introduce a methodology that can be used for identifying turmoil periods on a datadriven basis. We employ the previous results in the analysis of the contagion issue between Asian and American stock markets. Our results shows some evidence of contagion and the proposed statistics identifies, on a data-driven basis, turmoil periods consistent with the ones currently assumed in the literature.
\end{abstract}

\section{Keywords}

Financial market contagion, Market linkages, Variance spillovers, Dynamic correlations, Rolling correlations, Transformed correlations

\section{JEL Codes}

G15, F3, C22, C32

\author{
Address for correspondence: \\ Monica Billio \\ Department of Economics \\ Ca' Foscari University of Venice \\ Cannaregio 873, Fondamenta S.Giobbe \\ 30121 Venezia - Italy \\ Phone: (++39) 0412349170 \\ Fax: (++39) 0412349176 \\ e-mail: billio@unive.it
}

This Working Paper is published under the auspices of the Department of Economics of the Ca' Foscari University of Venice. Opinions expressed herein are those of the authors and not those of the Department. The Working Paper series is designed to divulge preliminary or incomplete work, circulated to favour discussion and comments. Citation of this paper should consider its provisional character.

\footnotetext{
${ }^{1}$ This paper benefits from the financial support of the MIUR project "The linkages between economic cycle and financial variables: interdependence and real effects of financial fluctuations”. The authors gratefully acknowledge research assistance from the GRETA Associati staff and in particular from Ludovic Cales, Giulia Mazzeo and Nicolò Schiavon. The paper content greatly improved thanks to interesting discussions with Michael McAleer, Loriana Pelizzon, Domenico Sartore, Paolo Paruolo and Olivier Scaillet. We thank also the comments received at the SER2006 conference held in Rome, Italy, the TSEFAR 2006 conference organised in Perth, Australia, the ESEM 2006 meeting held in Vienna, Austria, the CFE07 Workshop organised in Geneva. The Working Paper Series Department of Economics is availble only on line Ca' Foscari University of Venice (www.dse.unive.it/pubblicazioni) Cannaregio 873, Fondamenta San Giobbe For editorial correspondence, please contact: $\quad 30121$ Venice Italy wp.dse@unive.it Fax: ++390412349210
} 


\section{Introduction}

The last two decades have experienced a series of financial and currency crises, many of them carrying regional or even global consequences: the 1987 Wall Street crash, the 1992 European monetary system collapse, the 1994 Mexican pesos crisis, the 1997 "Asian Flu", the 1998 "Russian Cold", the 1999 Brazilian devaluation, the 2000 Internet bubble burst and the default crisis in Argentina of July 2001. Most of these crises hit emerging markets, which are more sensitive to shocks because of their underdeveloped financial markets and their large public deficits. The common feature shared by these events was that a country specific shock spreads rapidly to other markets of different sizes and structures all around the world.

It is still quite puzzling to justify the reason why a country reacts to a crisis affecting another country to which the former is not linked by any strong economic fundamentals. Many authors dealing with the topic of international propagation of shocks have referred to this circumstance as a contagion phenomenon, even if there is still no agreement on which factors lead to identify a contagion event precisely, and it is not yet clear how to define the contagion event itself.

Referring to the World Bank's classification, we can distinguish three definitions of contagion:

-Broad definition: contagion is identified with the general process of shock transmission across countries. The latter is supposed to work both in tranquil and crisis periods, and contagion is not only associated with negative shocks but also with positive spillover effects;

-Restrictive definition: this is probably the most controversial definition. Contagion is the propagation of shocks between two countries (or group of countries) in excess of what should be expected by fundamentals and considering the co-movements triggered by the common shocks. If we adopt this definition of contagion, we must be aware of what constitutes the 
underlying fundamentals. Otherwise, we are not able to appraise effectively whether excess co-movements have occurred and then whether contagion is displayed.

-Very restrictive definition: this is the one adopted by Forbes and Rigobon (2000). Contagion should be interpreted as the change in the transmission mechanisms that takes place during a turmoil period. For example, the latter can be inferred by a significant increase in the cross-market correlation. As we have said, this is the definition that will be used in this paper.

Many papers have focused on the question of contagion, testing for its existence with statistical methods. Their approaches vary with regard to the definition of contagion they choose as a starting point. As we have anticipated we will use the third definition.

Why do we concentrate on this aspect of contagion? Why this definition of contagion is important as is its exploration? Because, as observed by Forbes and Rigobon (2000), the other definitions of contagion and relative approaches of analysis are unable to shed light on three main issues: international diversification, evaluation of the role and the potential effectiveness of international institutions and bail-out funds, and propagation mechanisms. Indeed, a critical assumption of investment strategies is that most economic disturbances are country specific. As a consequence, stock in different countries should be less correlated. However, if market correlation increases after a bad shock, this would undermine much of the rationale for international diversification.

There is now a reasonably large body of empirical work testing for the existence of contagion during financial crises. A range of different methodologies are in use, often making it difficult to assess the evidence for and against contagion, and particularly its significance in transmitting crises between countries.

The origins of current empirical studies of contagion stem from Sharpe (1964) and Grubel and Fadner (1971), and more recently from King and Wadhwani (1990), Engle, Ito, and Lin 
(1990), and Bekaert and Hodrick (1992). Many of the methods proposed in these papers are adapted in some form to the current empirical literature on measuring contagion ${ }^{1}$. In particular, there now exists a range of statistical procedures to test for contagion. Some examples are the Forbes and Rigobon (2002) adjusted correlation test, the Favero and Giavazzi (2002) outlier test, the Pesaran and Pick (2004) threshold test, the Bae, Karolyi and Stulz (2003) co-exceedance test which contains as a special case the Eichengreen, Rose and Wyplosz $(1995,1996)$ probability model test, and the Dungey, Fry, González-Hermosillo and Martin $(2002,2004)$ factor test.

The variety of empirical methods developed for the analysis of contagion has the aim of testing the stability of parameters in the sphere of a chosen econometric model. Evidence of parameter shifts is a signal of a change in the transmission mechanisms, so according to the third definition there has been contagion. If, on the contrary, the parameters are constant, we should move to an interdependence case. Several methodologies have been used to statistically search for contagion in this way. However, the methodologies listed above carry some imperfections because the data often suffer from heteroskedasticity, endogenous and omitted variable problems. Some authors have tried to solve these problems, also in a similar way, although they have reached different conclusions in terms of contagion.

In particular, Forbes and Rigobon (2002) developed a correlation analysis adjusting correlation coefficients only for heteroskedasticity under the assumption of no omitted variables or simultaneous equations problems. Corsetti et al. (2002) built up a model in which the specific shock of the country under crisis does not necessarily act as a global shock because this could bias the analysis in favour of interdependence instead of contagion. The authors therefore introduce more sophisticated assumptions about the ratio between the

\footnotetext{
${ }^{1}$ Rigobon (2001) and Dungey et al. (2004) offer a good survey of these procedures, which are mainly based on OLS estimates (including GLS and FGLS), Principal Components, Probit models and correlation coefficient analysis. A useful reference is also Dungey and Tambakis (2005).
} 
variance of the country-specific shock and the variance of the global factors weighted by factor loadings ${ }^{2}$.

Concerning the omitted variable problem, it is important to identify common shocks which impact upon all countries simultaneously (Pritsker, 2002), or within regions (Glick and Rose, 1999). In either case, these shocks do not represent pure contagion, but also reflect the economic and financial linkages that exist between countries during non-crisis periods ${ }^{3}$. A failure to model common shocks may result in tests of contagion being biased towards a positive finding of contagion.

There are two broad approaches to identifying common shocks. The first is based on selecting a set of observable variables to act as proxies for the common shocks (Forbes and Rigobon, 2002; Bae, Karolyi and Stulz, 2003; and Eichengreen, Rose and Wyplosz, 1995, 1996). The second approach treats the common shocks as latent and models their dynamics. In their contagion tests Forbes and Rigobon (2002) filter out the common shocks by using estimated residuals from a VAR (see also Baig and Goldfajn (1999) for a further application of this approach). Favero and Giavazzi (2002) and Pesearan and Pick (2004) also use a VAR to identify common shocks which, in turn, are included as additional variables in a structural model. Dungey, Fry, González-Hermosillo and Martin (2002, 2004) explicitly treat the common shocks as latent and model their dynamics jointly with the potential linkages arising from contagion.

Nevertheless, all these tests are still highly affected by the choice of the window and its length (see Billio and Pelizzon, 2003; and Billio, Pelizzon and Lo Duca, 2003a) and the time zone, which often implies the use of a two day moving average and thus the introduction of noise in the data.

\footnotetext{
${ }^{2}$ See also Billio, Pelizzon and Lo Duca (2003b).

${ }^{3}$ These linkages are sometimes referred to as fundamentals based contagion (Kaminsky and Reinhart, 2000; Dornbusch, Park and Claessens, 2000).
} 
In this paper we propose a rather different approach. Instead of working with two-day moving averages of daily returns to avoid the time zone problem, we propose to work directly with the daily returns and to model directly the market relations also dealing with the time zone problem. We thus introduce a simultaneous equation system with a set of identifying parameter restrictions which comes from the true market timing. Furthermore, in order to model the variance spillovers we introduce a multivariate ARCH model. We also develop a measure of contagion which allows a simple graphical analysis of turbulence periods. Moreover, thanks to the proposed concordance and strength indicators we can also measure the intensity the signals of contagion. Finally, our methodology permits the identification of crisis and possibly distinguishes contagion from another effect which we label as flight-toquality.

In our approach, contagion is associated to an increase in the correlations among markets, while flight-to-quality occurs when correlations decrease. Note that our approach belongs to the strand of the literature that associates contagion to movements of the correlation matrix and thus we will assume that all other parameters of our model will be stable over time. The mean and variance structure which we estimate represents the information transmission mechanism that exists among financial markets. We can then associate this transmission mechanism to the interdependence, i.e. if our model shows no relations in the mean and in the variance in a set of stock market returns, we may say that the markets we are considering are not interdependent. However, they could be correlated and we may interpret correlation as a measure of integration among financial markets. Following this concept, contagion may thus be associated to a transitory increase in the integration among markets while flight-to-quality should signal a temporary decrease in the integration. However, distinguishing between temporary and permanent movements in the correlation matrix may not be so easy. The 
methodology we propose detects movements in the correlation matrix, and in general we may associate them to transitory changes.

The results we obtain with our approach may have relevant impacts for financial issues, mainly related to the optimal reaction of portfolio managers to a turmoil period. Making a parallel with the introduction of Forbes on his book on contagion (see Classens and Forbes, 2001), knowing how the disease evolves may help on finding the appropriate immunization and the preferred medicine. In a simple empirical example based on Asian and American markets we show that our approach correctly identifies the Asian crisis and could be used to infer the length of the turmoil periods. In fact, the data-driven turmoil periods we identify are comparable to the ones of Forbes and Rigobon (2002). Notably, where the two authors did not find evidences of contagion, our model indicates a relevant change in the correlation structure after taking into account both the mean and the variance dynamics.

Finally, the approach presented in this paper will possibly enable a detection of contagion occurrences and a real time detection of turmoil periods. This last point is left to future researches.

The outline of the paper is as follows. We introduce our approach, the correlation distance metric and the concordance and strength indicators in Section 2. In Section 3 we present some empirical evidence of contagion and flight-to-quality on six stock market indices and Section 4 concludes.

\section{Analysing correlation movements}

The current practice in contagion analysis to use two-day moving averages of daily returns often introduces moving average structures in the series, since the daily returns have no 
structure (or a very limited dependence) in mean. For this reason, in the following we suggest to work directly with daily data.

We collect the relevant market indices in the $n$-columns matrix $X_{t}=\left\{X_{1 t}, X_{2 t}\right\}$ which we partition into two subsets of dimension $n_{1}$ and $n_{2}$, respectively. Furthermore, we assume that the two subsets refer to groups of indices which we assume to be non-overlapping in terms of market timing. In order to illustrate our approach, we assume that these two groups correspond to the Asian $\left(X_{1 t}\right)$ and American $\left(X_{2 t}\right)$ markets, which, by construction, are nonoverlapping. Assume also that the day starts at the change-of-the-date Pacific meridian. As a consequence, Asian markets open in day $t$ before American markets ${ }^{4}$. These two market groups will also be analysed in the empirical example.

Note that, at day $t$ the closing levels of the indices included in $X_{1 t}$ is known before the markets covered by $X_{2 t}$ open; therefore, we may expect a contemporaneous relation from the first group to the second one, but not the opposite. This consideration of non-overlapping markets allows us to avoid the use of moving averages if we assume that all markets within a specific area are synchronous ${ }^{5}$.

Given this market structure, we specify a simultaneous equation system of the type

$$
A X_{t}=\sum_{i=1}^{5} B_{i} X_{t-i}+\varepsilon_{t}
$$

\footnotetext{
${ }^{4}$ In principle we can define a different "day" assuming that it starts from, say, the Greenwich meridian. In that case, the implied ordering of stock markets would be reversed with American markets opening before Asian markets. Consequently, the simultaneous equation system defined in the following would model simultaneous relations between American markets at time $t$ and Asian markets at time $t+1$.

${ }^{5}$ If within a specific area markets are non-synchronous the following analysis could be influenced since we assume synchronicity.
} 
where we include five lags in order to take into account some possible short memory autocorrelation and weekly effects. Furthermore, lags will be useful for model identification. Finally, we assume that the error term is characterised by a variance covariance matrix $\Sigma_{t}$.

When the matrices $A, B_{1}, B_{2}, B_{3}, B_{4}, B_{5}$ and $\Sigma$ are full, the system is under-identified. To achieve identification we impose the following restrictions:

i) given the market timing within the day and the absence of overlap between the two market groups, there is no contemporaneous causality from $X_{2 t}$ to $X_{1 t}$. This fact implies a set of $n_{1} \times n_{2}$ zero restrictions on the matrix $A$ as follows:

$$
A=\left[\begin{array}{cc}
A_{11} & 0_{n_{1} \times n_{2}} \\
A_{12} & A_{22}
\end{array}\right]
$$

ii) we impose the traditional $n_{1}+n_{2}$ normalization restrictions on the diagonal elements of $A$;

iii) finally, we impose the remaining set of $n_{1}\left(n_{1}-1\right)+n_{2}\left(n_{2}-1\right)$ zero restrictions on the fourth lag coefficient matrix of the autoregressive polynomial ${ }^{6}$.

Note that the restriction i) limits only some of the contemporaneous effects which are in any case possible within each group and from $X_{1 t}$ to $X_{2 t}$ (we can thus have Asian markets influencing American ones and contemporaneous effects within American or Asian markets). Furthermore, note that, given our hypothesis on the information flow between markets we may expect that the first lag coefficient matrix has the following structure:

$$
B_{1}=\left[\begin{array}{cc}
B_{11} & B_{12} \\
0_{n_{2} \times n_{1}} & B_{22}
\end{array}\right]
$$

\footnotetext{
${ }^{6}$ Note that the choice of using the fourth lag is arbitrary, we could have considered the second or third. We exclude the first and the fifth given that assuming zero restrictions could be a stronger assumption.
} 
where there is no effect from $X_{1 t-1}$ to $X_{2 t}$ given that all the relevant information has already been included in the contemporaneous relation.

We can thus consider the proposed model as a special case of a simultaneous equation system where the predetermined variable matrix includes only lagged dependent values of the endogenous variables. In fact, the model is also close to a structural VAR, whether we do not impose restrictions on the structural coefficient matrices but on the lagged coefficient matrices.

We can estimate the model by standard approaches like Two-Stage-Least-Squares or Instrumental Variables using as instruments further lags of the endogenous variables. Once the model is estimated and additional zero restrictions imposed and tested we can compute the residuals. Whenever additional restrictions appear on the data, this allows removing the constraints posed on the fourth-order lagged matrix. By that approach, the starting identifying restrictions can be rotated in the model in order to test their validity.

Our mean model will evidence any relation within market returns. The relevant coefficients could represent the standard news transmission mechanism operating in the financial markets. For simplicity we assume that the mean model is not affected by the turmoil periods, i.e. we assume that the parameters are stable on the whole sample. The estimated coefficients would enable an interpretation of the mean relationships between the considered markets.

Since our interest is to focus on contagion, defined as a structural break in the correlations, we must remove any spillover effect among variances. In fact, we assume that the spillover effects are a consequence of the contagion issue and simply spread the shocks among the markets. In this view and from a theoretical point of view, we may have no spillover effect within a contagion model, where the shocks just increase the correlation among countries. However, in real markets, contagion is in most cases associated with an increase in the 
variances, thus if we do not correctly filter out variance movements, including therefore in the model spillover effects, there is a risk of misperception of the contagion phenomenon.

We thus estimate on a univariate basis a set of GARCHX models (GARCH models with exogenous terms in the conditional variance equation) on each residual series:

$$
\begin{aligned}
\varepsilon_{j, t} & =\sigma_{j, t} z_{j, t} \\
\sigma_{j, t}^{2} & =\omega_{j}+\beta_{j} \sigma_{j, t-1}^{2}+\sum_{i=1}^{K} \alpha_{j, i} \varepsilon_{i, t-1}^{2}
\end{aligned}
$$

where the exogenous variables in the variance equation are the squared residuals of the other returns series.

Note that this model is a special case of the VARMA-GARCH of Ling and McAleer (2003). As Ling and McAleer do, we assume constant conditional correlation and, implicitly, assume that it is equal to the sample correlation. Our set of GARCHX models corresponds to a multivariate GARCH model with spillover only in the ARCH part of the model. Note that in this way we presume that the coefficients are stable over time and therefore changes in the correlation structure do not produce effect on the spillover transmission mechanism ${ }^{7}$. Finally, in order to allow for a two-step estimation procedure, we assume that the mean and variance coefficients are independent. Note that this approach induces a reduction in the estimator's efficiency.

Given the estimates of the variances, we compute the standardised residuals series $z_{j, t}$, which should contain information referred to the correlations only. However, the correlation may not be stable in the short run and could evidence relevant changes. Our main interest resides in the identification of these movements which could be associated to contagion occurrences.

\footnotetext{
${ }^{7}$ The generalisation of the model including time-varying coefficients within a rolling window approach has not been considered at this stage where we prefer to present our methodology.
} 
We do not follow the standard practice of the Dynamic Conditional Correlation models introduced by Engle (2002) and prefer to work on a partially non-parametric basis. We choose to estimate the correlation matrices on two non-overlapping but consecutive ${ }^{8}$ rolling windows of fixed length $m$ (our empirical analysis suggest to consider windows length running from 60 to 120 days), which we denote by

$$
\begin{gathered}
R_{1, t}=\left[r_{i j, 1, t}\right] \quad r_{i j, 1, t}=\frac{\sum_{l=t-m+1}^{t}\left(z_{i, l}-\bar{z}_{i, 1}\right)\left(z_{j, l}-\bar{z}_{j, 1}\right)}{\sqrt{\sum_{l=t-m+1}^{t}\left(z_{i, l}-\bar{z}_{i, 1}\right) \sum_{l=t-m+1}^{t}\left(z_{j, l}-\bar{z}_{j, 1}\right)}} \quad \bar{z}_{i, 1}=\frac{1}{m} \sum_{l=t-m+1}^{t} z_{j, l} \\
R_{2, t}=\left[r_{i j, 2, t}\right] \quad r_{i j, 2, t}=\frac{\sum_{l=t+1}^{t+m}\left(z_{i, l}-\bar{z}_{i, 2}\right)\left(z_{j, l}-\bar{z}_{j, 2}\right)}{\sqrt{\sum_{l=t+1}^{t+m}\left(z_{i, l}-\bar{z}_{i, 2}\right) \sum_{l=t+1}^{t+m}\left(z_{j, l}-\bar{z}_{j, 2}\right)}} \quad \bar{z}_{i, 2}=\frac{1}{m} \sum_{l=t+1}^{t+m} z_{j, l}
\end{gathered}
$$

Given these two estimates of the correlation matrix, we compare them by using some metrics. The simplest choice is

$$
d_{t}=\sum_{i=1}^{K} \sum_{j=i+1}^{K}\left(r_{i j, 2, t}-r_{i j, 1, t}\right)
$$

which allows us to evidence average increases and decreases of the correlations. We simply call it "distance" metric". We also consider other metrics, like the squared discrepancies, the sum of eigenvalues, the minimum or maximum eigenvalues but the results turned out to be more convincing with the first simpler choice.

\footnotetext{
${ }^{8}$ The two windows can also be not consecutive but separated by a finite number of observations in order to exclude turmoil periods or extreme events which can affect the sample correlation estimate. The inclusion of some space between the windows will be used in the empirical analysis included in this paper.

${ }^{9}$ Note that the metric we are using is not really a distance since it assumes also negative values.
} 
The plot of the distance metric allows the graphical analysis of correlations by evidencing possible peaks, which will be then associated to relevant increases/decreases of the correlation. Clearly, we may expect that shorter the length of the window noisier will become the plot since it will react even to short-term movements in the correlations. For this reason, we may suggest two alternative strategies depending on the analysis final purpose: if the objective is the dating of contagion occurrences we suggest using quite large values of $m$, starting from 90 days (i.e. 4 months) to 120 days (half an year); differently, if the interest is in the real time detection of possible contagion and crisis transmission, shorter windows can be used (normally between 20 an 60 days, i.e. from 1 to 3 months), having clear in mind that a false positive may in some cases be obtained. In the last case, we can also consider two windows of different lengths, the second, containing the more recent data, shorter than the first one.

A deeper analysis may also consider non contiguous windows, leaving then some space between them. In that case, several metrics could be compared allowing a better identification of relevant changes as we will show in the empirical part of the present paper.

This graphical analysis is not statistically significant since we are not able to distinguish relevant changes from irrelevant ones. In statistics there exists a transformation of the correlation coefficient which turns out to be useful in our case, the Fisher $z$-transformation (Fisher, 1915):

$$
\rho_{l, i j, t}=\frac{1}{2} \log \left(\frac{1+\hat{r}_{i j, t}}{1-\hat{r}_{i j, t}}\right) \quad l=1,2 \quad i, j=1,2 \ldots k \quad i \neq j
$$


where $i$ and $j$ define the involved variables, $t$ refers to time and $l$ to the window considered and the hat denotes sample estimates. This transformation returns a variable with a known asymptotic distribution

$\rho_{l, i j, t} \sim N\left(\mu_{l, t}, \sigma_{l}^{2}\right) \quad \mu_{l, t} \simeq \frac{1}{2} \log \left(\frac{1+r_{l, i j, t}}{1-r_{l, i j, t}}\right) \quad \sigma_{l}^{2} \simeq \frac{1}{N-2}$

which allows us to derive the distribution of a transformed "distance" metric. In fact, for each difference of the same correlation coefficient obtained in the two samples, we can derive a standard test of the equality of two populations mean with unknown variance. We can thus test the null hypothesis of equal means in (8)

$H_{0} \quad \mu_{1, t}=\mu_{2, t}$

using the following test statistic

$Q_{t}=\frac{\rho_{2, i j, t}-\rho_{1, i j, t}}{\sqrt{s_{2, i j, t}+s_{1, i j, t}}}$

where the variances are replaced by their sample estimator. The treatment of our setup is well known in statistics as the Behrens-Fisher problem, whose discussion can be found in Sheffé (1970). The test statistic is asymptotically distributed as a standardised normal but it has not the standard $t$-distribution in small samples, and must be approximated following Sheffé (1970). 
There are relevant hypothesis to be explicitly stated, namely the independence between samples, which may be true whether correlations are not dynamic, and the independence between the transformed correlations included in the distance metric. Notably, Dungey et al. (2005) show that the use of two non-overlapping windows in testing for contagion has relevant consequences for the power of the test in finite samples ${ }^{10}$.

When considering several correlations at the same time we must include in the test statistic the estimate of the covariance matrix. Rao (1979) provides the multivariate distribution of the Fisher transformation applied to a vector of correlations computed on $k$ different variables. Let $q=k(k-1) / 2, \quad p=\operatorname{vecu}(R)$ (where vecu stacks the lower triangular part of the population correlation matrix $R$ excluding diagonal terms), and $\varepsilon=F T(p)$ is the vector of the transformed true correlations and $T$ is the sample length. Then, Rao (1979) shows that the vector of the estimated transformed correlations $e=F T(\operatorname{vecu}(\hat{R}))$ follows the multivariate normal distribution $e \sim N(\varepsilon, V / T)$ where the variance-covariance matrix has the following elements

$$
\begin{aligned}
& V_{a, a}=\operatorname{Var}\left(e_{i j}\right)=1 \\
& V_{a, b}=\operatorname{Cov}\left(e_{i j}, e_{k l}\right)= \\
& =\frac{\rho_{i k} \rho_{j l}+\rho_{i l} \rho_{j k}-\rho_{k l}\left(\rho_{i k} \rho_{j k}+\rho_{i l} \rho_{j l}\right)-\rho_{i j}\left(\rho_{i k} \rho_{i l}+\rho_{j k} \rho_{j l}\right)+\frac{1}{2} \rho_{i j} \rho_{k l}\left(\rho_{i k}^{2}+\rho_{i l}^{2}+\rho_{j k}^{2}+\rho_{j l}^{2}\right)}{\left(1-\rho_{i j}^{2}\right)\left(1-\rho_{k l}^{2}\right)}
\end{aligned}
$$

and $\rho_{j l}$ identifies population correlations.

\footnotetext{
${ }^{10}$ For example the Forbes and Rigobon (2002) test, which considers two overlapping windows, is undersized (consistently with much of the empirical literature where empirical studies find little evidence of contagion when using this test) and it can be fix in many cases by taking the crisis and noncrisis periods as disjoint samples.
} 
Using this result, the variable $e^{\prime} i_{k}$, which is the sum of the various transformed correlations, follows a normal distribution of the type $e^{\prime} i_{k} \sim N\left(\varepsilon^{\prime} i_{k}, i_{k}{ }^{\prime} V i_{k} / N\right)$, from which we can derive the multivariate representations of equations (9) and (10):

$H_{0}: \varepsilon_{1, t}=\varepsilon_{2, t}$

$Q_{t}=\frac{e_{2, t}^{\prime} i_{k}-e_{1, t}^{\prime} i_{k}}{\sqrt{i_{k}^{\prime} \hat{V}_{2, t} i_{k} / N+i_{k}^{\prime} \hat{V}_{1, t} i_{k} / N}}$

where 1 and 2 identify the two non-overlapping windows and we replace the variancecovariance matrices with the sample estimators based on the estimated correlations. Furthermore, we can redefine the vector of ones $i_{k}$ as a selection variable that focuses only on some correlations, in order to distinguish changes in the correlation level within a subset of the variables under analysis.

A rejection of the null hypothesis indicates a structural break in the correlation matrix which, in our setup, corresponds to an evidence of relevant movement in the correlations. Therefore, by plotting the test statistics and the critical values over time we obtain a graphical tool that would evidence critical situations. Furthermore, the sign of the test statistic is informative: contagion is defined as an average increase in stock market correlations, therefore it is associated to positive values of the metric distance statistics (in case of rejection of the null hypothesis of equal correlations in the two non-overlapping windows); differently, a negative value of the test statistics is associated to an average decrease of stock market correlations, a fact which is normally identified as flight-to-quality. The test statistics computed on a rolling basis provides results comparable to a resampling procedure. In that case, we should expect rejections of the null hypothesis in a number of cases close to the confidence interval level. 
The test statistics we propose should provide a higher frequency of rejections in order to evidence occurrences of contagion.

The statistic we propose can be used to detect relevant movements in the correlation matrix at a given point in time. In order to identify only extreme movements we suggest choosing very high significance levels, i.e. higher than the 95\%. Furthermore, our approach could provide important information about the length of the turmoil periods, by analysing the ranges for which the test statistics provide a rejection of the null hypothesis. However, given that the test statistics can be computed on a set of possible windows lengths, and with several data points that separate the two windows, we need a method for compressing the information.

For that purpose, we suggest a method adopted in business cycle analysis. We compute a 'concordance' indicator as follows: i) first, we calculate a set of test statistics varying the window length and/or the space between the two windows; ii) then, we align the test statistics in such a way that the beginning of the second window is the same for all of them (this step allows to assign the signals of contagion or flight-to-quality to a fixed point in time, specifically the point at which the second window begins); iii) we thus derive two indicator variables for each of the test statistics, the first identifying periods where the test statistics evidence contagion, the second for flight-to-quality occurrences; iv) finally, we sum up the test statistics obtaining a concordance indicator (standardising it with the number of test statistics used, $K)$.

Given this concordance indicator, we can identify the turmoil periods as the periods where the indicator is larger than 0.5 (at least $50 \%$ of the test statistics identifies a change in the correlation matrix). Furthermore, in order to avoid false signals or to misinterpret extreme returns or common shocks as contagion, we may require that a turmoil period should last for at least, say, 5 days (i.e. one week).

The 'concordance' indicator we suggest for contagion has the following representation: 
$C I_{t}=\frac{1}{K} \sum_{j=0}^{K} I_{j, t}\left(\operatorname{sign}\left(Q_{t}\right)=+\mid H_{0}\right.$ rejected $)$

where $K$ is the maximum step between the two windows and it is equal to 120 days; $I_{t, j}(\bullet)$ is an indicator function assuming the values 1 if the condition between parenthesis is true; $H_{0}$ is the null hypothesis to be tested, i.e. the equality of the correlation matrix in the two subsamples, and $\operatorname{sign}(\cdot)$ refers to the sign of the quantity between parenthesis. Note that contagion is associated to positive sign conditionally to the rejection of the null hypothesis while flight-to-quality is associated to negative test statistics, again conditionally to the rejection of the null hypothesis.

Referring again to the business cycle literature, concordance indices monitor the agreement between cyclical phases at a given point in time, but carry no information about persistence of the phases. For this reason, we could also introduce a 'strength' or 'severity' indicator, which is similar to the $C I_{t}$ index, but where the elements we sum up are the cumulated values of the indicator functions over a given window:

$S I_{t}=\sum_{j=0}^{K}\left(\sum_{l=t-K+1}^{t} I_{j, l}\left(\operatorname{sign}\left(Q_{t}\right)=+\mid H_{0}\right.\right.$ rejected $\left.)\right)=\sum_{j=0}^{K} W_{t, j}$

In that case, the quantities $W_{t, j}$ monitor the persistence of rejections of the null hypothesis. They are given by the sum of indicator variables over the last $K$ points in time, with $K$ is set to 120, the maximum lag used between the two subsamples included in the test statistics. Again, we standardise it with the number of test statistics used, i.e. $K^{2}$. 
According to the literature, we also evaluate our approach using two overlapping windows. By this approach we should be able to distinguish increases in correlations not necessarily associated to a contagion occurrence as noted in Dungey et al. (2005). Following Forbes and Rigobon (2002), we consider as our first window the total sample and we adopt a rolling procedure affecting only the second window. Furthermore, we will let the second window vary from 30 to 120 days and we will compact the results using a concordance indicator as in the previous case.

\section{Empirical analysis}

The dataset used includes the closing levels of daily stock market index for six countries (USA, Mexico, Brazil, Hong Kong, Singapore and Japan) together with their exchange rates with respect to the US Dollars (USD). The sample runs from the $20^{\text {th }}$ June 1995 to the $16^{\text {th }}$ November 2005. Note that longer daily series are available for all countries but this is not true for the exchange rates with respect to the USD. Therefore, we preferred to restrict the sample to compare the analysis based on local currency and USD valued indices over a common sample. The six indices and the five exchange rates have been homogenised on a common time scale replacing missing values with a zero return.

In the empirical analyses we consider two alternative cases: the indices expressed in local currency (that is the original stock market index level) and the indices expressed in a common currency, i.e. US dollars (obtained converting the stock market index level into US dollars). Furthermore, in order to obtain consistent USD-valued stock market indices, the exchange rates have been recorded at the closing of the local market. That is, the exchange rate between the Japan Yen and the US Dollar is recorder at the close of the Japan stock market. By that 
approach, the exchange rates and the stock market indices are influenced by a common information set.

We consider the Asian markets as synchronous even if this is not exactly the case: a preferred approach should be based on stock market indices recorded at a fixed point over the day when all Asian area markets are open. This procedure will avoid any possible problem due to nonsynchronous trading. Unfortunately, this type of data is not available to us. A further comment refers to the exclusion of European markets. We are aware to miss a relevant area; however, its inclusion would have required a different treatment given the overlap with American markets. At this point, our main purpose is to introduce a different approach useful to identify contagion occurrences, and to show that even with a limited number of markets it provides relevant results. An extension of the proposed setup for modelling synchronous trading within area markets and between area overlapping markets will be the object of future research.

We do not report for brevity the tables collecting, for both local currency and US dollar indices cases, the estimated coefficients of the simultaneous equation system and the estimated coefficients of the GARCHX models ${ }^{11}$. In all cases, we followed a general to specific modelling strategy by successively imposing several zero restrictions on the general models. The estimated coefficients are all statistically significant even if we have not reported the relevant robust standard errors. Tables 1 and 2 resume all the significant relations, which are also showed in Figures 1, 2 and 3.

The simultaneous equation system estimates evidence that relevant contemporaneous relations exist between Asian markets and South American markets (for both the cases considered). Within American markets, as expected, we find a relevant effect from the US to Brazil and Mexico. Furthermore, among the Asian markets, Hong Kong plays a central role,

\footnotetext{
${ }^{11}$ These are available from the authors upon request.
} 
influencing most markets both within the area and in America. These comments do not change by taking into account the currency.

As expected, the lagged variable coefficients show the impact of US returns on most countries when we use the local currencies. Differently, when we add the exchange rates effects Japan emerge as a relevant market driver. Even in that case, Hong Kong seems to be a relevant source and a relevant receiver of information since it appears in several equations. On the remaining lags, there are no relevant market links. The limited appearance of lagged relations on the American markets may be explained by their inclusion in the contemporaneous matrix. In fact, we may presume that contemporaneous coefficients and relations carry the most relevant part of information. The GARCH estimates point out the existence of spillover effects coming mostly from the US and Hong Kong markets, in most cases and independently on the currency used. Furthermore, when referring to the USD based series, Singapore appears as a relevant market.

Given the mean and variance standardised residuals, we compute the test statistics for the correlation movements using a window length of 120 observations (which broadly correspond to 6 months). In this first analysis the windows are contiguous. We consider the tests on the full set of correlations.

When moving to the analyses of the metric and of the test for changes in the correlation matrix, we evidence an effect associated to the rolling window approach: the distance metric and the test statistics are affected by extreme events entering and exiting form the first and from the second window. These extreme realizations create a "wave" on the test statistic which becomes before very high and then evidences a sharp drop. This is particularly evident for the 11 September 2001. This event is clearly not a contagion issue but an extreme event affecting all world market indices. As a consequence, in order to avoid noisy effects coming 
from this peculiar extreme event we decided to remove it replacing the VAR-GARCHX residuals of $11 / 9$ with a zero (which is the average).

We also verified that this event is really extreme by computing the quantile under a normal multivariate distribution with data expressed both in local currencies and in US dollars. This analysis is not reported here for brevity but clearly evidences the relevance of this event.

Figure 4 reports the metric based both on original and transformed correlation changes. The graph evidences that the two approaches provide very close patterns, suggesting that the Fischer-z transformation can be safely used as an alternative measure for testing correlation movements. Furthermore, Figure 4 shows the so called wave effect which is evident around the second part of 2001, when we can note very wide movements which are separated by 120 days.

\subsection{An analysis excluding the 11 September}

We applied our methodology for analysing correlation movements on the residuals obtained excluding the 11 September 2001. We considered windows length of 120 days (approximately equal to six months) both contiguous and separated by 1 to 120 days. Some of the obtained test statistic series are reported in Figures 5 and 6 both for the local currency case and for the series in US dollars. We reported a subset of the possible cases, for contiguous windows and for a step of 1, 2, 3 and 6 months. In all cases, the test statistics use a $1 \%$ twosided confidence interval. The rejection frequencies of the null hypothesis are larger that the expected probability under a resamplig-like scheme, suggesting that the rejections are not type I errors.

We can note on the graphs that the test statistics follow similar patterns, in particular when evidencing a rejection of the null hypothesis of equal correlation matrices over the two 
windows. Both figures suggest a relevant correlation movement around 1997, during and after the Asian crisis. The two approaches show some differences in the second part of the sample, suggesting that the correlation movements that took place during this period were not common to stock and exchange rate markets.

To obtain a more consistent dating of turmoil periods we computed the proposed concordance and strength indicators by summing the rejections of the null hypothesis. In that step we distinguished between average increases and decreases of the correlation levels. The concordance indicators are reported in Figure 7. We first focus on contagion, which we associate to an average increase of the correlation level. Both US dollars and local currency approaches provide clear evidence of contagion for the Asian crisis, as Figures 5 and 6 suggested. Differently, other relevant changes in the correlation matrices are not coherent in the two cases, also for the one detected in the second half of 2003, and probably associated to the Iraq war. Figure 8 reports the strength indicator that confirms the findings of the concordance indicator.

In order to distinguish between relevant occurrences of contagion and possible statistical errors (a type I error under a resampling-like scheme), we state that correlation movements should be evident on at least 60 of our 121 test statistics (value determined on the basis of the step between the windows), and should last for at least one week (that is, 5 observations). Under these rules, we evidence the periods reported in Table 3, where the day refers to the beginning of the second window. Both approaches evidence a relevant increase in the correlation matrices in the second part of 1997, a period generally associated to the Asian crisis. Furthermore, we compare our data-driven turmoil period with the a-priori fixed turmoil periods of Forbes and Rigobon (2003), which we reported in Table 4. Notably, our Asian crisis turmoil period corresponds to case ii) in Forbes and Rigobon (2003). It seems from our analysis that a contagion effect started when Thailand market went down and it continued up 
to December 1997 . We stress that our contagion period is not completely equivalent to the Forbes and Rigobon's one given that we used a data-driven approach. As a result, and using our methodology, we can state that during the second part of 1997 contagion took place in a set of interdependent markets.

Our analysis uses a sample period larger that the traditional studies on contagion. As a result we are able to identify additional turmoil periods and to distinguish if these were associated to relevant movements in the stock markets, in the exchange rate markets or in both, as in the case of the Asian crisis. In particular we evidence two additional turmoil periods, the first of them ranges from the end of June 2001 to mid August 2001. It can be associated to relevant movements in the exchange rate market given that it appears only when the series are valued in the common currency. A second crisis period starts in June 2003 and ends in September 2003. As the previous one, it could be associated to movements in the exchange rate markets, probably due to the Iraq war.

Moving to the flight-to-quality evidences, we noted only a single limited period, between September and December 2004 and again on the exchange rates market only. This could be associated to a group of events: long term effects of the Iraq war and of the Argentina default; starts of the increases in oil prices; start of the boom of China and India economies and contemporaneous stagnation of Sud America economies.

Finally, as previously discussed, similar analysis could be arranged using overlapping windows. An example is included in Figure 9, where we report the graph of the concordance indicator for contagion using series expressed in USD. This indicator is clearly useless and our empirical analysis suggests that this approach may induce substantial biases in the turmoil periods, an effect of the possible distortions of the tests also noted by Dungey et al. (2005). For this reason we have not adopted this alternative approach in the empirical analysis. 
Summarising, using the approach proposed in the current paper and a limited markets sample we evidenced periods of contagion and flight-to-quality. The periods we determined are consistent with other approaches available in the literature.

\section{Conclusions}

This paper introduces a new approach for testing for contagion. Differently from traditional approaches based on two-days moving averages of stock market returns, we model by a simultaneous equation system the overlapping and contemporaneous market relations, introducing also lagged values to include in the model mean effects up to one week. Furthermore, we also model variance spillovers by a special multivariate GARCH model built on the general representation of Ling and McAleer (2003). In our model only the ARCH part has a multivariate structure while the GARCH one has only one source of persistency, the one of the considered series. Finally, we analyse the correlations on a non-parametric basis using the Fischer z-transformation. This transformation allows the construction of a test for changes in correlations taking advantage of its asymptotic distribution. We compare correlation on consecutive non-overlapping windows, possibly separated by a number of days. Given the numerous test statistics we can compute at a given point in time (one for each distance we impose between the sub-samples used), we propose a way for summarizing the information content of the tests. We propose two indicators inspired by the business cycle literature: a concordance and a strength indices.

On an empirical basis, we demonstrate the advantages of our approach evidencing contagion and flight to quality phenomena. As an additional result, we can also identify mean relations and variance spillovers. Finally, our empirical analysis allows also distinguishing the effects absorbed by exchange rate movements from that directly transmitted to stock markets. 


\section{References}

Bae, K.H, Karolyi, G.A. and Stulz, R.M. (2003), A New Approach to Measuring Financial Contagion, Review of Financial Studies, 16(3), 717-763.

Baig, T. and Goldfajn, I. (1999), Financial Market Contagion in the Asian Crisis, IMF Staff Papers, 46(2), 167-195.

Bekaert, G. and Hodrick, R. (1992), Characteristing Predictable Components in Excess Returns on Equity and Foreign Exchange Markets, Journal of Finance, 47, 467-509.

Billio M. and L. Pelizzon (2003), Contagion and Interdependence in Stock Markets: Have they been misdiagnosed?, Journal of Economics and Business, 55, 5/6, 405-426.

Billio M., M. Lo Duca and L. Pelizzon (2003a), Contagion and interdependence measures: some words of caution, Working paper 0302 GRETA, Venice.

Billio M., M. Lo Duca and L. Pelizzon (2003b), The DCC test: powerless evidence of no contagion, Working paper 0307 GRETA, Venice.

Classens, S. and K. Forbes (2001), International financial contagion, Springer.

Corsetti G., M. Pericoli and M. Sbracia, 2002, Some contagion, some interdependence more pitfalls in tests of financial contagion, Discussion Paper n. 3310, CEPR.

Dornbusch, R., Park, Y.C. and Claessens, S. (2000), Contagion: Understanding How it Spreads, The World Bank Research Observer, 1 5(2), 1 77-97.

Dungey, M. and D. Tambakis (2005), Identifying International Financial Contagion: Progress and Challenges, Oxford University Press, New York.

Dungey, M. and D. Tambakis (2005), International Financial Contagion: What Do We Know?, chapter 1 in M. Dungey and D. Tambakis (eds), Identifying International Financial Contagion: Progress and Challenges, Oxford University Press, New York. 
Dungey, M., R. Fry, B. Gonzalez-Hermosillo and V.L. Martin (2005), Sampling Properties of Contagion Tests, mimeo Australian National University.

Dungey, M., R. Fry, B. Gonzalez-Hermosillo and V.L. Martin (2005a), Empirical Modelling of Contagion: A Review of Methodologies, Quantitative Finance, 5/1, 9-24.

Dungey, M., R. Fry, B. Gonzalez-Hermosillo and V.L. Martin (2005b), A Comparison of Alternative Tests of Contagion with Applications, chapter 3 in M. Dungey and D. Tambakis (eds), Identifying International Financial Contagion: Progress and Challenges, Oxford University Press, New York.

Eichengreen, B., Rose, A.K. and Wyplosz, C. (1995), Exchange Market Mayhem: The Antecedents and Aftermath of Speculative Attacks, Economic Policy, 21, 249-312.

Eichengreen, B., Rose, A.K. and Wyplosz, C. (1996), Contagious Currency Crises, NBER Working Paper, 5681.

Engle R.F. (2002), Dynamic conditional correlation: a new simple class of multivariate GARCH models, Journal of Business and Economic Statistics, 20, 339-350.

Engle R.F., Ito, T. and Lin, W. (1990), Meteor Showers or Heat Waves? Heteroscedastic Intra-Daily Volatility in the Foreign Exchange Market, Econometrica, 5 8, 525-542.

Favero, C.A. and Giavazzi, F. (2002), Is the International Propagation of Financial Shocks Non Linear? Evidence from the ERM, Journal of International Economics, 57(1), 231246.

Fisher, R.A. (1915), Frequency distribution of the values of the correlation coefficient in samples of an indefinitely large population, Biometrika, 10, 507-521 
Forbes K. and R. Rigobon (2000), Measuring contagion: conceptual and empirical issues, in S.Claessens and K. Forbes (Eds), International Financial Contagion, Kluwer Academic Publishers.

Forbes K.J. and R. Rigobon (2002), No contagion, only interdependence: measuring stock market comovements, Journal of Finance, 57/5, 2223-2261.

Glick, R. and Rose, A.K. (1999), Contagion and Trade: Why are Currency Crises Regional?, Journal of International Money and Finance, 18(4), 603-17.

Grubel, H.G. and Fadner R. (1971), The Interdependence of International Equity Markets, Journal of Finance, 26, 89-94.

Kaminsky, G.L. and Reinhart, C.M. (2000), On Crises, Contagion and Confusion, Journal of International Economics, 51(1), 145-168.

King, M. and Wadhwani, S. (1990), Transmission of Volatility Between Stock Markets, Review of Financial Studies, 3 (1), 5- 33.

Ling, S. and M. McAleer (2003), Asymptotic theory for a vector ARMA-GARCH model, Econometric Theory, 19, 278-308.

Pesaran, H. and Pick, A. (2004), Econometric Issues in the Analysis of Contagion, CESifo Working Paper No. 1176.

Pritsker, M. (2002), Large Investors and Liquidity: A Review of the Literature, in Committee on the Global Financial System (ed), Risk Measurement and Systemic Risk, Proceedings of the Third Joint Central Bank Research Conference.

Rao, D.C. (1979), Joint distribution of z-tranformations estimated from the same sample, Human Heredity, 29, 334-336

Rigobon R. (2001), Contagion: how to measure it?, NBER Working Paper No. w8118. 
Scheffé, H. (1970), Practical solutions to the Behrens-Fisher Problem, Journal of the American Statistical Association, 65, 1501-1508

Sharpe, W. (1964), Capital Asset Prices: A Theory of Market Equilibrium Under Conditions of Risk, Journal of Finance, 19, 425-42.

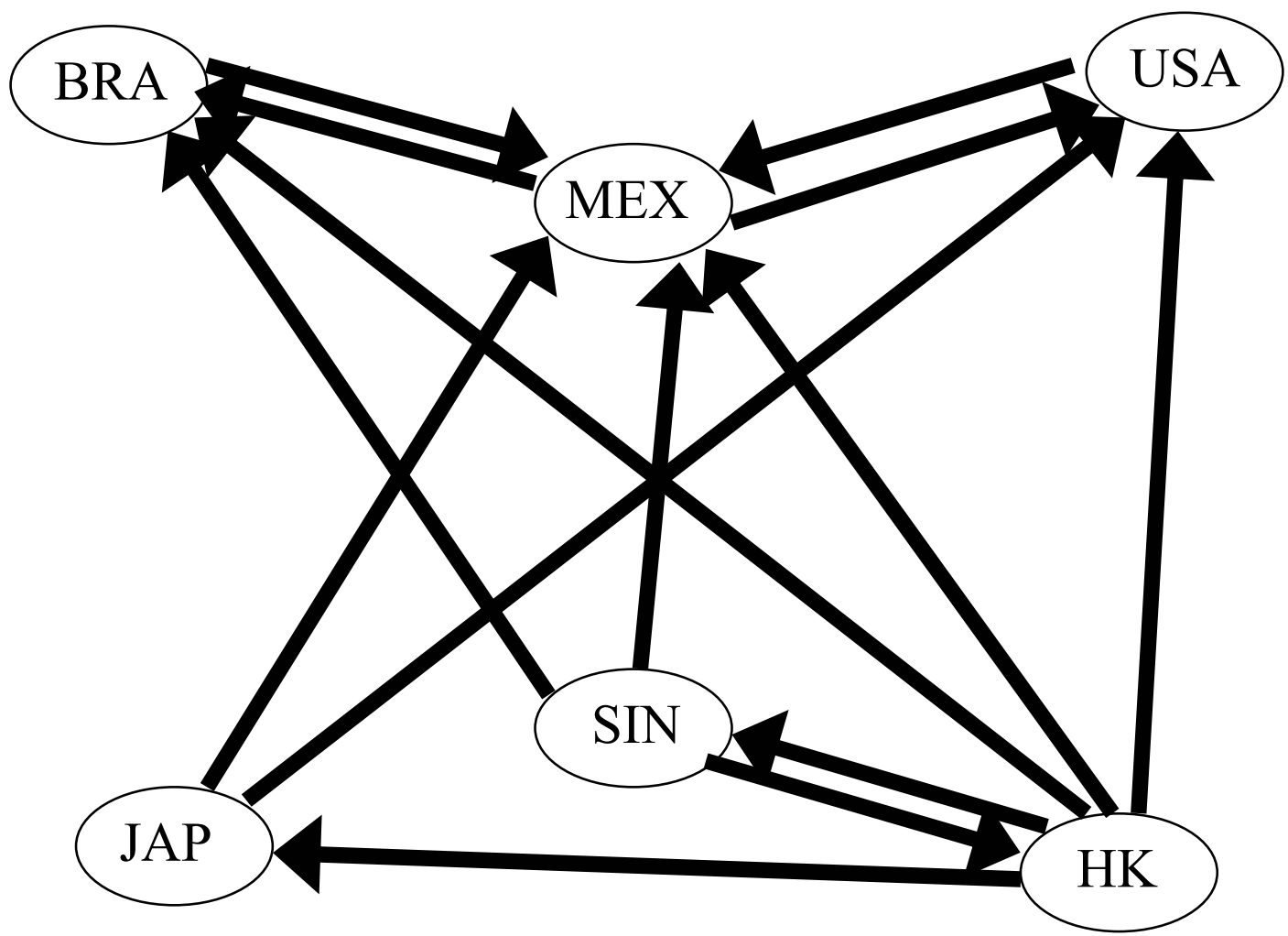

Figure 1: Simultaneous mean effects among the USA, Mexican (MEX), Brazilian (BRA), Hong Kong (HK), Singapore (SIN) and Japanese (JAP) stock markets. 


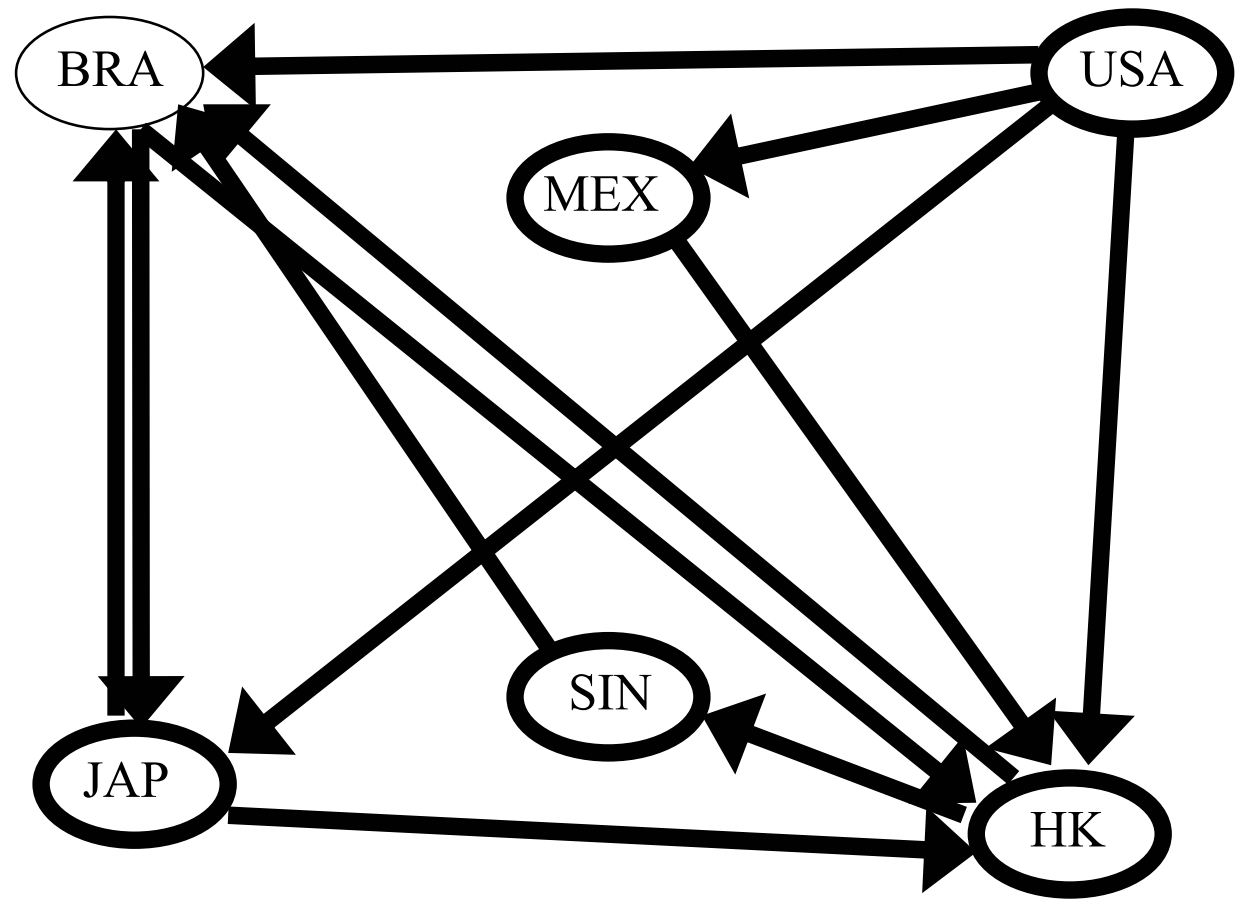

Figure 2: First lag mean effects among the USA, Mexican (MEX), Brazilian (BRA), Hong Kong (HK), Singapore (SIN) and Japanese (JAP) stock markets.

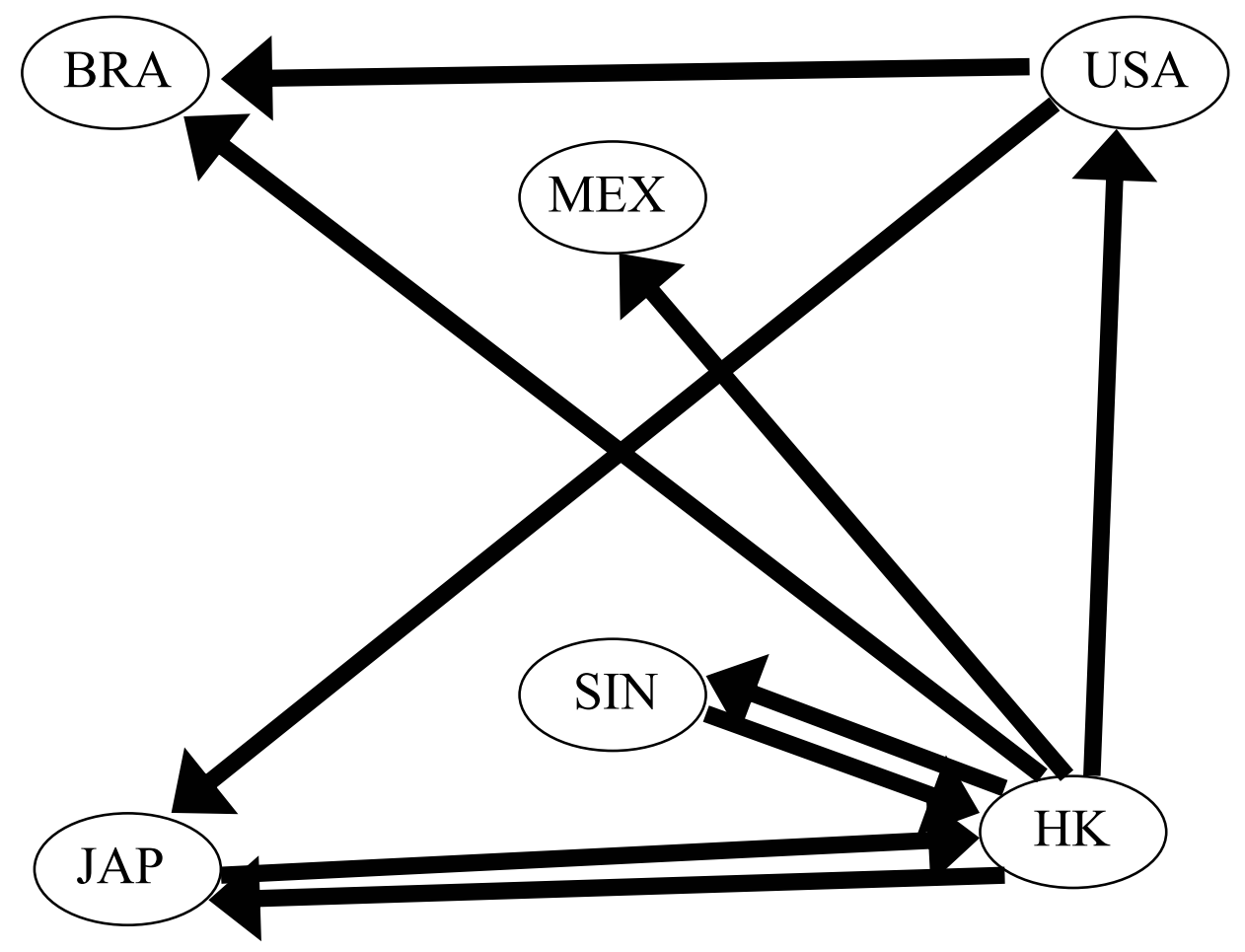

Figure 3: Spillovers in the variance equations among the USA, Mexican (MEX), Brazilian (BRA), Hong Kong (HK), Singapore (SIN) and Japanese (JAP) stock markets. 


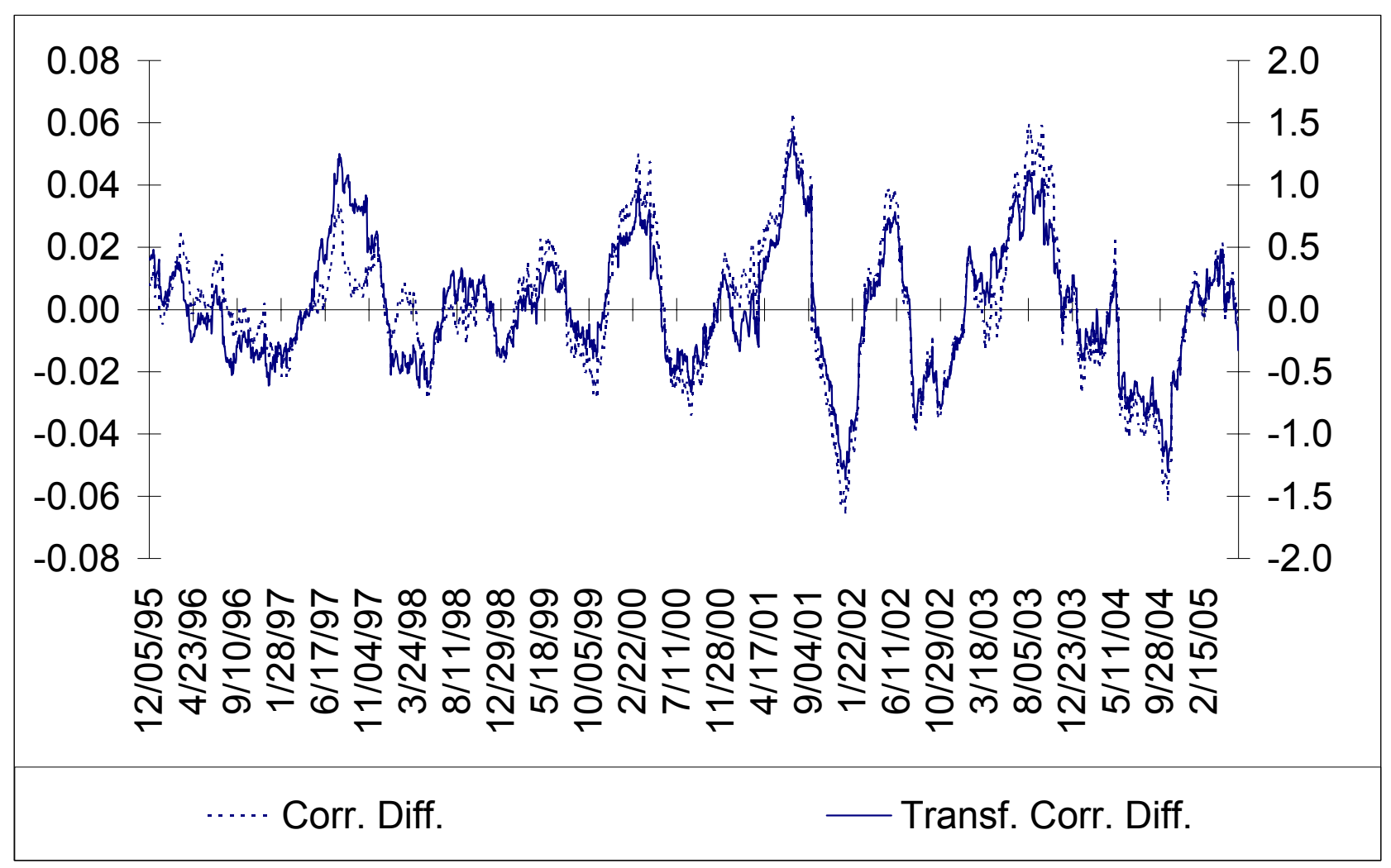

Figure 4: Distance metric based on original and transformed correlations.

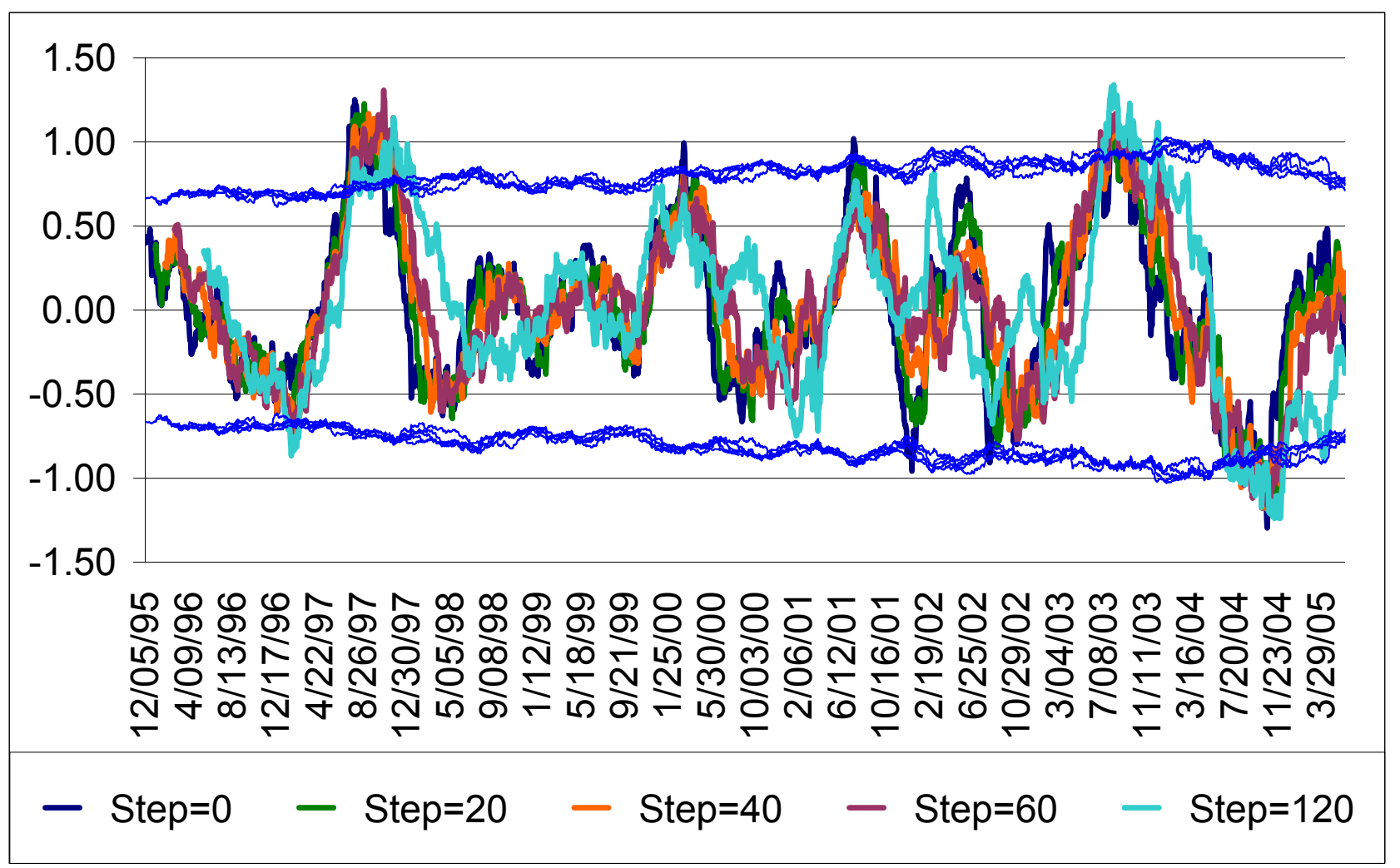

Figure 5: Test statistics for changes in the correlation matrix with different steps between the two windows considered - data in US dollars - confidence bounds in blue. 


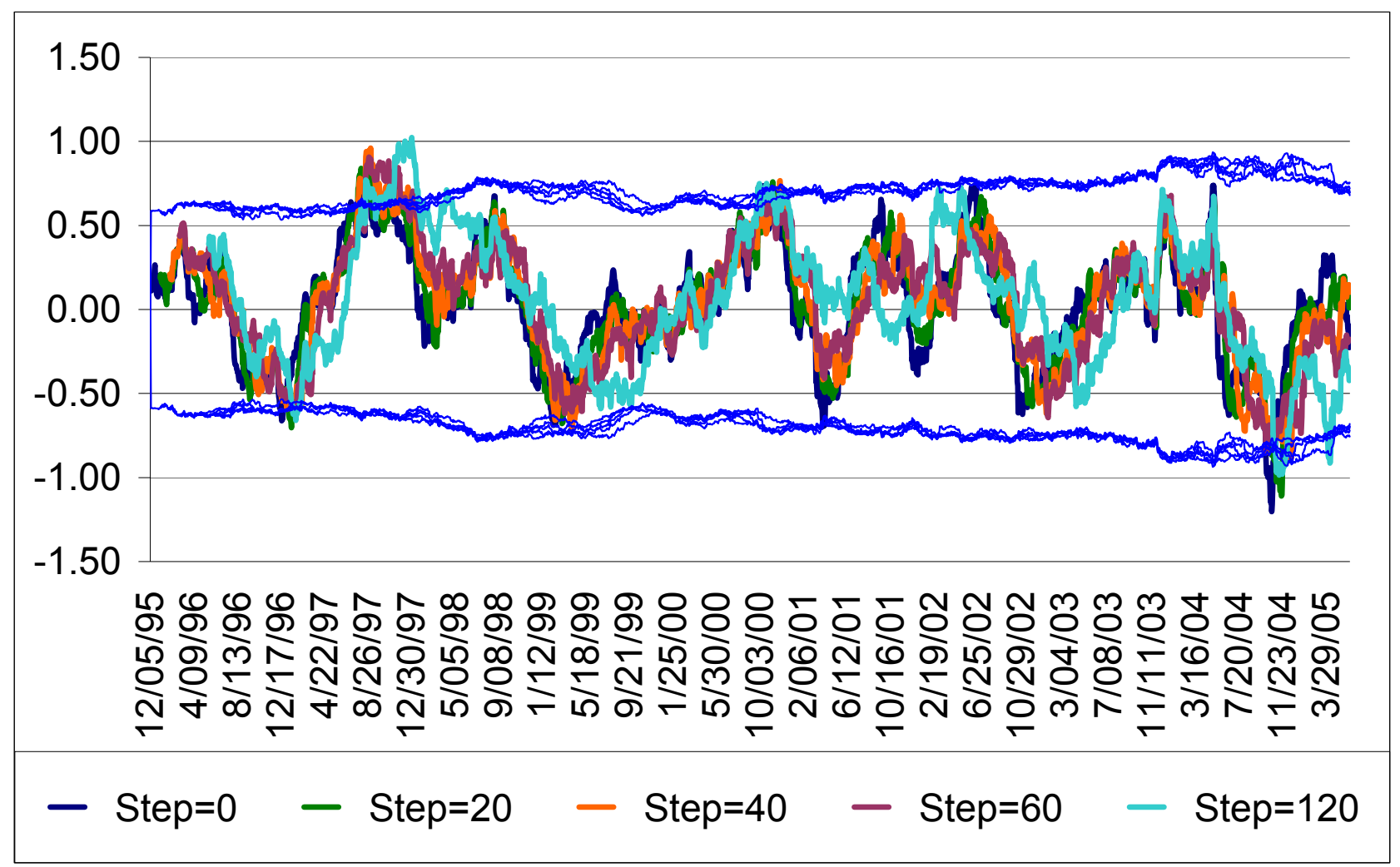

Figure 6: Test statistics for changes in the correlation matrix with different steps between the two windows considered - data in local currency - confidence bound in blue.

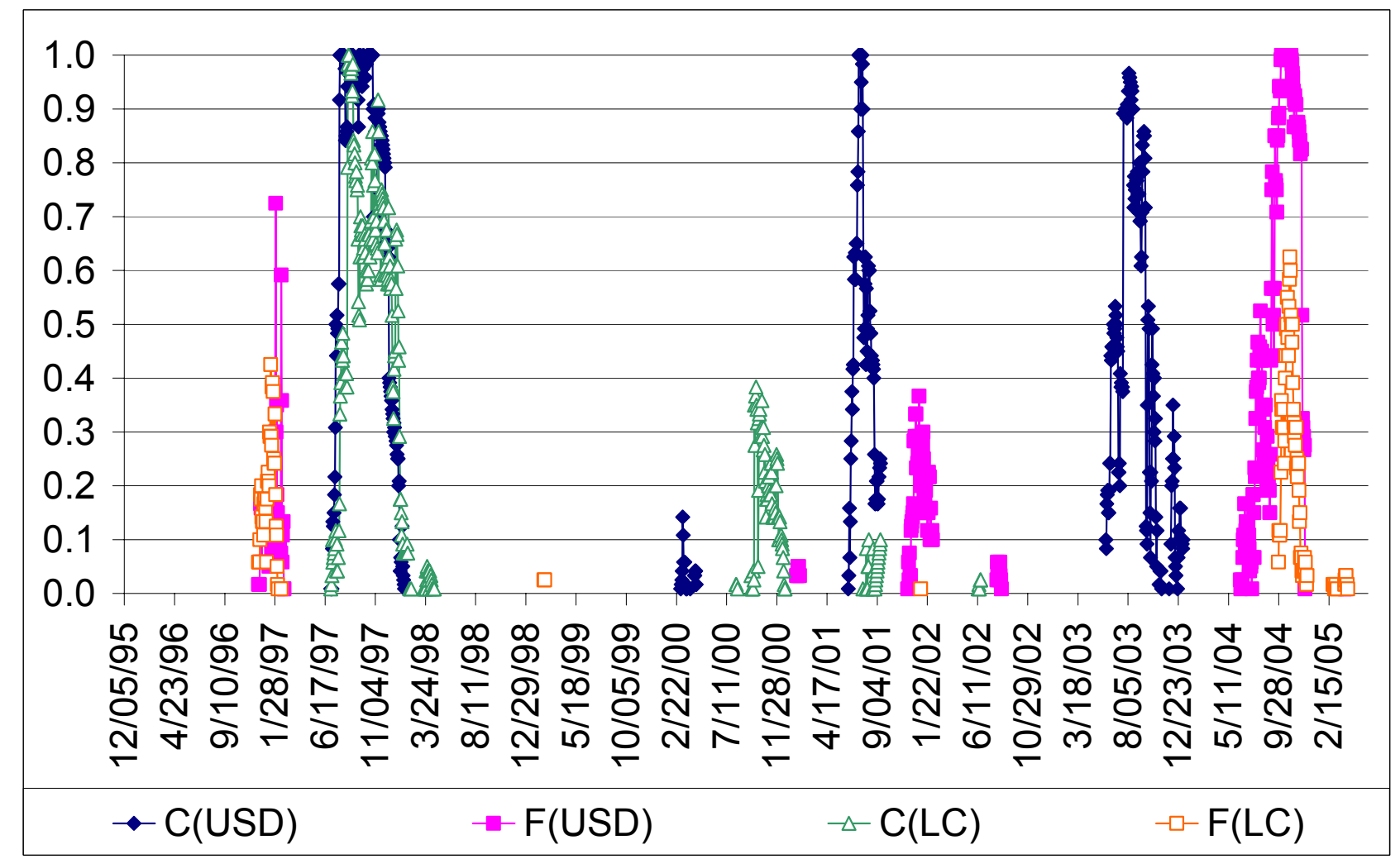

Figure 7: Concordance indicator on contagion $(C)$ and flight to quality $(F)$ phenomena based on a set of test statistics for a change on the correlation matrix - data both in USD and local currency (LC). 


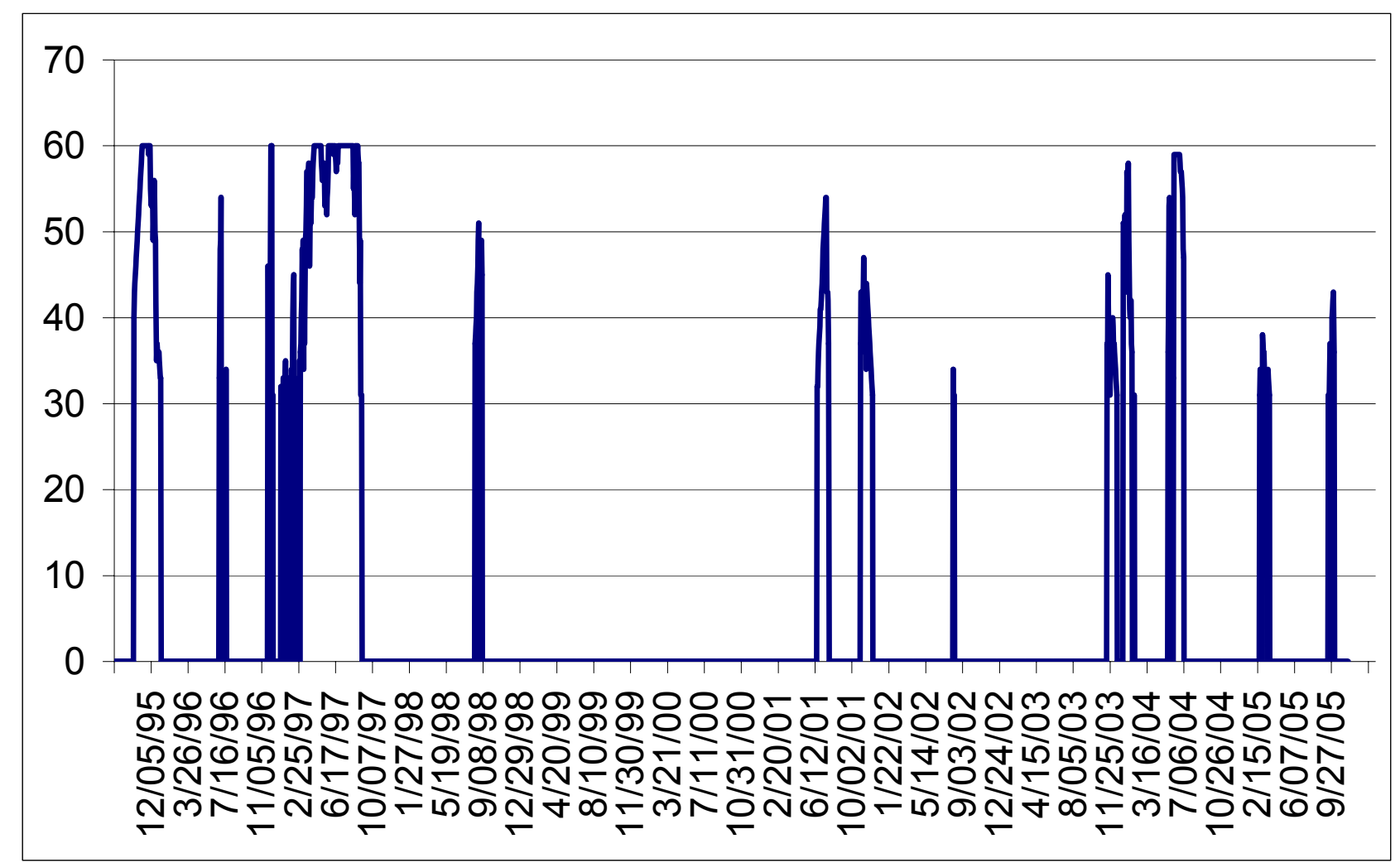

Figure 8: Concordance indicator for contagion among USD based indices.

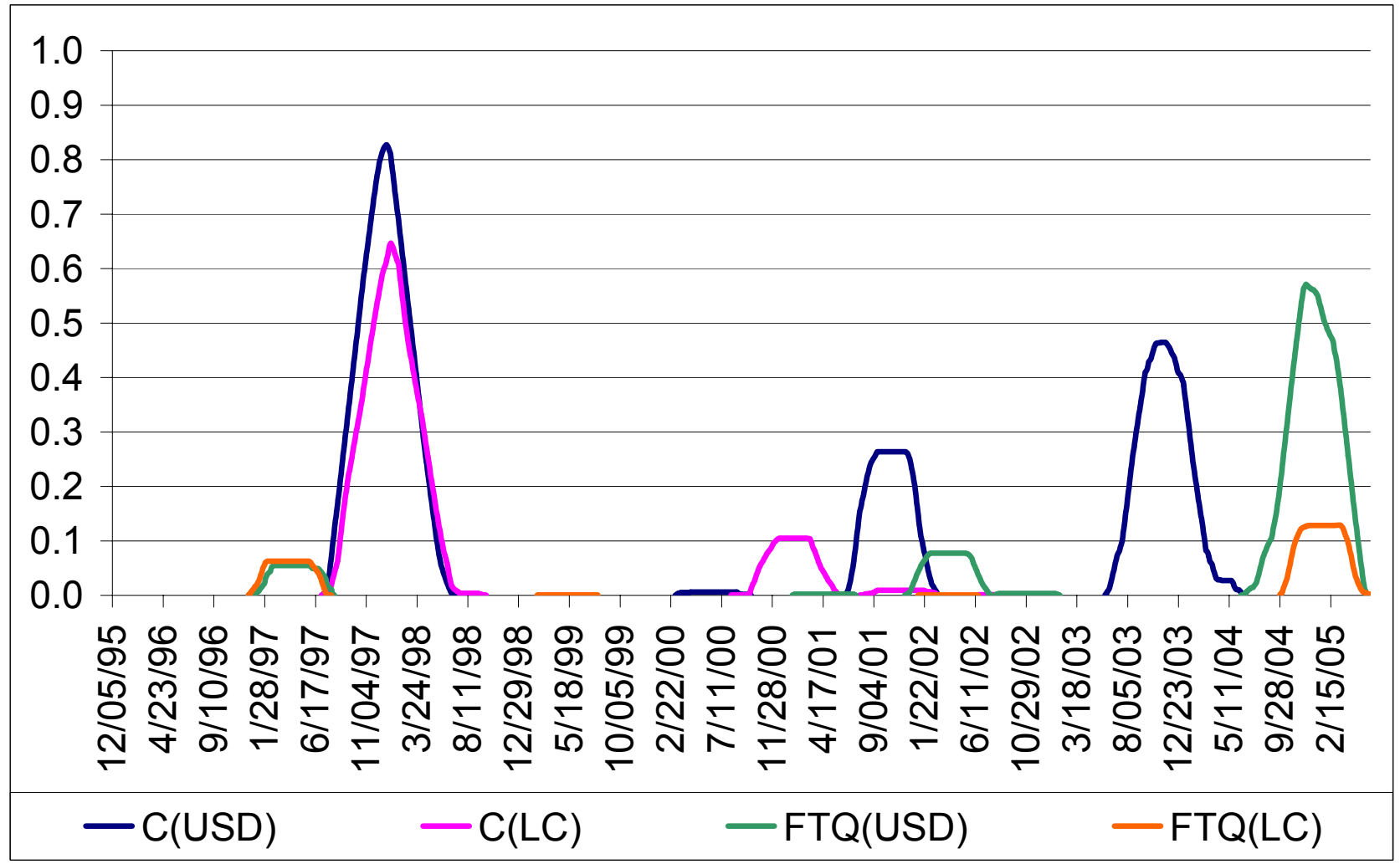

Figure 9: Strength indices on contagion $(C)$ and flight to quality $(F)$ phenomena on a set of test statistics for a change on the correlation matrix - data both in USD and local currency (LC). 


\begin{tabular}{|c|c|c|c|c|c|c|c|}
\hline \multirow[t]{2}{*}{$\begin{array}{l}\text { Index } \\
\text { equation }\end{array}$} & \multicolumn{7}{|c|}{$\begin{array}{l}\text { Significant relations - coefficient in the Simultaneous Equation Systems and in } \\
\text { the GARCH models }\end{array}$} \\
\hline & $t$ & $t-1$ & $t-2$ & $t-3$ & $t-4$ & $t-5$ & GARCH \\
\hline BRA & $\begin{array}{c}\text { MEX, } \\
\text { USA, JP, } \\
\text { HK }\end{array}$ & JP & USA, JP & & & USA & $\begin{array}{l}\text { USA, } \\
\text { SIN }\end{array}$ \\
\hline MEX & $\begin{array}{c}\text { BRA, } \\
\text { USA, JP, } \\
\text { HK }\end{array}$ & JP & $\begin{array}{c}\text { BRA, } \\
\text { MEX, JP }\end{array}$ & & & MEX & $\begin{array}{l}\text { USA, } \\
\text { SIN }\end{array}$ \\
\hline USA & $\begin{array}{c}\text { BRA, } \\
\text { MEX, JP, } \\
\text { HK }\end{array}$ & JP & JP & & & & SIN \\
\hline HK & SIN & $\begin{array}{l}\text { BRA, } \\
\text { MEX, } \\
\text { USA, } \\
\text { HK, JP }\end{array}$ & $\begin{array}{c}\text { USA, JP, } \\
\text { HK }\end{array}$ & $\begin{array}{c}\text { USA, } \\
\text { HK, SIN }\end{array}$ & $\mathrm{HK}$ & $\begin{array}{c}\text { MEX, } \\
\text { USA }\end{array}$ & JP, SIN \\
\hline JP & HK & $\begin{array}{c}\text { BRA, } \\
\text { USA, JP, } \\
\text { HK }\end{array}$ & USA & & & & USA, HK \\
\hline SING & $\mathrm{HK}$ & $\mathrm{HK}$ & $\begin{array}{l}\text { USA, JP, } \\
\text { HK, SIN }\end{array}$ & & HK & $\begin{array}{l}\text { MEX, } \\
\text { USA }\end{array}$ & $\begin{array}{l}\text { BRA, } \\
\text { USA, HK }\end{array}$ \\
\hline
\end{tabular}

Table 1: Summary of relevant relations in the simultaneous equation system and in the conditional variance models - indices expressed in US dollars.

\begin{tabular}{|c|c|c|c|c|c|c|c|}
\hline \multirow[t]{2}{*}{$\begin{array}{l}\text { Index } \\
\text { equation }\end{array}$} & \multicolumn{7}{|c|}{$\begin{array}{l}\text { Significant relations - coefficient in the Simultaneous Equation Systems and in } \\
\text { the GARCH models }\end{array}$} \\
\hline & $t$ & $t-1$ & $t-2$ & $t-3$ & $t-4$ & $t-5$ & GARCH \\
\hline BRA & $\begin{array}{c}\text { MEX, } \\
\text { SING, } \\
\text { HK }\end{array}$ & $\begin{array}{c}\text { USA, } \\
\text { HK, } \\
\text { SIN, JP }\end{array}$ & & BRA & & $\begin{array}{l}\text { BRA, } \\
\text { USA }\end{array}$ & USA, HK \\
\hline MEX & $\begin{array}{c}\text { BRA, } \\
\text { USA, JP, } \\
\text { HK, SIN }\end{array}$ & $\begin{array}{l}\text { MEX, } \\
\text { USA }\end{array}$ & $\begin{array}{c}\text { BRA, } \\
\text { MEX, } \\
\text { HK }\end{array}$ & & & & HK \\
\hline USA & $\begin{array}{l}\text { MEX, JP, } \\
\text { HK }\end{array}$ & USA & $\begin{array}{l}\text { MEX, } \\
\text { BRA }\end{array}$ & & & & $\mathrm{HK}$ \\
\hline HK & SIN & $\begin{array}{c}\text { BRA, } \\
\text { MEX, } \\
\text { USA, JP, } \\
\text { HK }\end{array}$ & $\begin{array}{l}\text { BRA, } \\
\text { USA, } \\
\text { HK, JP }\end{array}$ & $\begin{array}{l}\text { USA, } \\
\text { HK, } \\
\text { SIN }\end{array}$ & HK & $\begin{array}{l}\text { MEX, } \\
\text { USA }\end{array}$ & $\begin{array}{l}\text { JP, } \\
\text { SIN }\end{array}$ \\
\hline JP & $\mathrm{HK}$ & $\begin{array}{l}\text { BRA, } \\
\text { USA, JP }\end{array}$ & USA, JP & & & & USA, HK \\
\hline SING & $\mathrm{HK}$ & $\mathrm{HK}, \mathrm{SIN}$ & $\begin{array}{l}\text { USA, } \\
\text { HK, SIN }\end{array}$ & SIN & $\mathrm{HK}$ & USA & HK \\
\hline
\end{tabular}

Table 2: Summary of relevant relations in the simultaneous equation system and in the conditional variances - indices expressed in local currency. 


\begin{tabular}{|c|c|c|}
\hline & USD based data & Local currency data \\
\hline \multirow{3}{*}{ 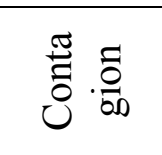 } & $23 / 07 / 97$ to $10 / 12 / 97$ & $18 / 08 / 97-06 / 01 / 98$ \\
\hline & $29 / 06 / 01$ to $14 / 08 / 01$ & \\
\hline & $22 / 07 / 03$ to $22 / 09 / 03$ & \\
\hline 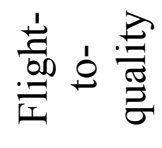 & $07 / 09 / 04$ to $01 / 12 / 04$ & \\
\hline
\end{tabular}

Table 3: Correlation and flight-to-quality occurrences.

\begin{tabular}{|c|c|}
\hline Start & End \\
\hline 17 Oct. 1997 (Hong-Kong down) & 16 Nov. 1997 \\
or & or \\
01 Jun. 1997 (Thailand down) & 23 Dec. 1997 \\
or & or \\
07 Aug. 1997 (Thailand and Indonesia down) & 01 Mar. 1998 \\
\hline
\end{tabular}

Table 4: Turmoil periods suggested by Forbes and Rigobon (2002) 